\title{
The Benefits of Attending Catholic Schools: A Look at the Academic-Achievement of African-American Boys in Elementary School
}

\author{
Roseanne L. Flores \\ Hunter College of the City University of New York, New York, USA \\ Email: rflores@hunter.cuny.edu
}

How to cite this paper: Flores, R. L. (2020). The Benefits of Attending Catholic Schools: A Look at the Academic-Achievement of African-American Boys in Elementary School. Open Journal of Social Sciences, 8, 489-505. https://doi.org/10.4236/jss.2020.85033

Received: April 23, 2020

Accepted: May 26, 2020

Published: May 29, 2020

Copyright (๑) 2020 by author(s) and Scientific Research Publishing Inc. This work is licensed under the Creative Commons Attribution International License (CC BY 4.0).

http://creativecommons.org/licenses/by/4.0/

\section{(c) (i) Open Access}

\begin{abstract}
African-American boys continue to struggle academically. Catholic schools have been found to have a positive effect on the academic achievement of minority students. Few studies have examined the relationship between attending Catholic elementary school and academic achievement for African-American boys. Using data from the 2012 Parent and Family Involvement in Education (PFI) survey, a survey of the National Household Education Program series, the purpose of the current study was to examine the relationship between school climate and academic achievement for African-American boys attending elementary school. Spearman correlations and logistic regressions were used to explore the relationship between overall school climate and academic achievement. Strong correlations were found between contacting parents about school behavior problems as well as successful school work and overall behavior, suggesting parental engagement has a positive effect on the academic outcomes of African-American boys.
\end{abstract}

\section{Keywords}

African-American, Boys, Catholic Schools, Academic Achievement, Elementary School, School Climate

\section{Introduction}

In 2011 the National Education Council Association released a brief entitled "Race Against Time: Educating Black Boys," which highlighted some of the ways the educational system was failing African-American boys. At that time, $42 \%$ of African-American boys were attending under-resourced schools of low quality and were three times more likely to be suspended or expelled from a school. 
These educational disparities when taken together often led to further alienation and isolation from peers. Moreover, only $2.5 \%$ of African-American boys were less likely to be in gifted and talented programs, whereas $85 \%$ of African-American and Latino males were in special education classes, with approximately $20 \%$ receiving a diagnosis of "mental retardation". In addition, the quality of education that African-American males received was further compromised by the quality of their teachers, with $28 \%$ of core teachers lacking appropriate certification. Over time, the combination of these events has come to function very much like quicksand; that is, the more African-American males panic and struggle to stay afloat, the quicker they sink, eventually giving up hope and drowning. For many boys, their continued struggle often leads to a failure to complete high school on time. Moreover, for those fortunate enough to finish high school and go unto college, many frequently become discouraged and fail to persist and complete a bachelor's degree (NEA, 2011).

Regrettably, this situation has not changed much since 2011. According to data from the 2015 report released from the Schott Foundation for Public Education entitled "Black Lives Matter. The Schott 50 State Report on Public Education and Black Males" Black males continue to be at the bottom of the four-year high school graduation rates in 35 out 48 states, and the District of Columbia, a gap which the foundation points out relegates Black males to a life of missed opportunities and poverty (Schott Foundation, 2015).

While these statistics look dismal, there is hope as previous research has also demonstrated that African-American males, growing up in low-income urban communities, do not always perform poorly in academic settings, but rather do quite well, and seem to thrive when their school climates are engaging and conducive to learning (Barbarin et al., 2014). Furthermore, previous research has demonstrated that when African-American boys have a positive attitude toward school, they are more likely to complete the academic school year (Belgrave \& Brevard, 2015). According to the University-Community Partnerships at Michigan State (2004a, 2004b), school climates refer to the psychological and physical components of the school that allow teaching and learning to occur. Optimal school climates share the following characteristics: the physical environment is orderly and inviting; the social environment encourages positive and inviting interactions between teachers, parents, and students; the teachers, parents, and students are respectful of one another providing a safe and welcoming environment; and finally the academic environment is structured to engage and promote learning. The question arises if African-American boys thrive in such school climates where can such climates be found in low-income communities? One answer can be found in Catholic schools, which appear to offer a school climate conducive to learning for urban low-income youth. Previous research has found that African-American and Latino youth from low-income communities who attended Catholic schools perform better academically than their peers who attended public school. This phenomenon has 
been labeled the "Catholic School Effect" (Greeley, 1982; Hoffer, Greeley, \& Coleman, 1985). The question nevertheless remains as to what is it about Catholic schools that produce this phenomenon.

\subsection{Brief Overview of the History of Catholic Education and African-Americans}

The Catholic Church, like the Quakers, has played an essential role in providing African-Americans with educational opportunities for many centuries (Dunn, 1960). While the Catholic Church in the United States shares in the guilt of the nation that in the 1800s often established separate schools for African-Americans which were not necessarily equal to those of their White peers, the church nevertheless should be credited with establishing schools when public education was not available to African-Americans (Dunn, 1960; Irvine \& Foster, 1996). For example, in 1829, the Oblate Sisters of Providence, the first religious order for African-American women, was founded in the United States. In turn, the sisters opened a school for African-American children in Baltimore, Maryland, as there was no public school either in Baltimore or within the United States at the time, which was open to African-American children (Dunn, 1960). According to Dunn (1960), the mission and vision of the Catholic Church were to establish schools to impart moral and spiritual values as well as to better the lives of humanity. In the case of African-Americans, that included providing them with the necessary skills they would need so that they could take part in the larger society and become leaders in their own right (Dunn, 1960).

\subsection{The Mission of Catholics School Today}

According to the United States Conference of Catholic Bishops one, the primary role of Catholic education is to ensure that children and youth receive a foundation spiritually, emotionally, and intellectually that will allow that to become successful and civic-minded adults. The USCCB asserts that "young people of the third millennium must be a source of energy and leadership in our church and our nation. Therefore, we must provide young people with an academically rigorous and doctrinally sound program of education and faith formation ..." Moreover, Catholic schools must "collaborate with parents and guardians in raising and forming their children as families struggle with the changing and challenging cultural and moral contexts in which they find themselves ..." (USCCB, 2006: p. 267). Thus the mission of Catholic schools is to educate the whole child, mentally, physically, spiritually, and emotionally (USCCB, 2015).

\subsection{The Importance of Elementary School}

During the elementary school years, children learn to read, write, critically think, and develop friendships. Elementary schools provide children with a foundation that is critical for future learning and school success. Previous research has 
demonstrated that African-American boys suffer from educational disparities before entry into elementary school (Joe \& Davis, 2009), therefore making it critical that their primary school experience is of the highest quality. Several characteristics have been identified in the literature as necessary for elementary schools serving low-income communities to be effective. First, it has been suggested that they have strong instructional leadership with a clear mission and communication and collaboration among the teaching staff. Second, it has been recommended that schools establish positive and supportive relationships with parents. Third, it has proposed that positive relationships be fostered between the school and the community. And finally, it has been suggested that schools provide students with teachers who understand the mission of the school, have high expectations for students, and who provide a positive school climate (University-Community Partnerships at Michigan State, 2004a). Elementary schools serving African-American boys would do well to embody these characteristics.

\subsection{The Role of Religion and Catholic School Education and African-Americans Today}

Today African-Americans continue to do less well academically than their White and Asian peers (Barbarin et al., 2104). For many, poor quality public elementary schools are their only option because they either do not possess the required scores to be accepted into specialized public schools or lack the financial resources necessary to attend private school. Catholic elementary schools provide an alternative to public education for those African-American families who choose them as an option. While Catholic schools in general, and those that support the needs of African-Americans in particular, face many challenges, such as decreased enrollment, decreased income from tuition and government vouchers, reduced support from more affluent families, and the steady decline of contributions from Catholics in general, Catholic schools nevertheless still have a critical role to play in the education of African-American youth by providing them with a solid academic foundation (National Black Catholic Congress, 2012). Moreover, previous research has demonstrated that religious institutions, particularly Black churches, have played a critical role in supporting spiritually, psychologically as well as materially the Black community helping them not only to survive but to thrive and succeed (Green, 2011). Also, the church has often served to provide families with a purpose and a strong identity (Marsh, Chaney, \& Jones, 2012). That being said, religious institutions have proven to be a strength for the African-American community, often leading to positive outcomes, the question that arises is whether Catholic elementary school will lead to higher academic achievement for African-American boys?

\subsection{Purpose of the Present Research}

To date, while several studies have been conducted to examine the effect of 
attending a Catholic high school on the academic achievement of minorities, few studies have focused on children in elementary and middle school (Fenzel \& Monteith, 2008; Fenzel \& Domingues, 2009). Moreover, few studies, if any, have addressed the relationship between attending Catholic elementary schools and the academic achievement of African-American boys.

To address the gap research, the purpose of the present study was to examine the relationship between school climate and the academic achievement of African-American boys attending public and Catholic elementary schools. This study builds upon previous research that examined the effect of attending Catholic school on the academic performance of African-American children, particularly high school students (Greeley, 1982). However, this study extends the literature by examining the relationship between the school climate as defined by children's enjoyment of school and parents' engagement with the school concerning their son's overall schoolwork and behavior. These two components have been identified as being critical for high academic performance. Furthermore, the study focuses on African-American boys attending elementary school as the primary population.

\section{Research Questions}

The research questions for the current study were as follows:

1) What are the overall characteristics of African-American boys and their families who attend public and Catholic elementary schools?

2) What is the prevalence of parents who report that their African-American boys enjoy school?

3) What is the incidence of absenteeism reported by parents of African-American boys attending elementary school?

4) What is the relationship between school climate and academic achievement?

5) Does school climate and attendance in Catholic schools predict better academic performance for African-American boys?

\section{Methods}

\subsection{Overview of the National Household Education Survey}

The National Household Education Survey (NHES) is a set of surveys funded and administered by the United States Department of Education. The NHES 2012 includes three topical surveys: the Parent and Family Involvement in Education (PFI) survey, the Parent and Involvement in Education Homeschool survey (PFI-Homeschooled), and the Early Childhood Program Participation (ECPP) survey. This paper uses data from the PFI survey.

Description of Parent and Family Involvement in Education Survey (PFI) The Parent and Family Involvement in Education Survey (PFI) was conducted using a nationally representative of noninstitutionalized students ages 4 through 18 or enrolled in school grades kindergarten through 12 or homeschooled. All 
children were from the 50 states and the District of Columbia. All data were collected from January through August 2012 by the United States Census Bureau. The NHES sample was selected using a two-stage address-based sampling method. During the first stage, residential addresses were selected. During the second stage, an eligible child was chosen from the information provided in the screener. African-Americans and Latinos were oversampled. Once the sample was selected, they were mailed printed questionnaires in English or Spanish. The respondents for this survey were parents or guardians living in the household who knew the child being sampled. The final number of completed PFI surveys was 17,563. All surveys were weighted to reflect the national population (Noel, Stark, \& Redford, 2013).

\subsection{Participants}

Data for this research was extracted from the Parent and Family Involvement in Education (PFI) National Household Education Surveys Program 2012. The focus of this study was African-American boys attending Catholic and public elementary schools. A total of 2707 children identified as Black, 1408 of them were boys, with 602 of them attending elementary school. Of the 602 boys attending elementary school, 555 were in public school, and 19 were in Catholic school. The remaining boys participated in a variety of other education options. Of the 602 African-American boys attending elementary school, 541 were between the ages of 10 - 14 years of age.

Parent and Family Involvement in Education Survey 2012

The PFI consists of eight sections which address questions concerning: 1) the child's schooling, 2) families and school, 3) homework, 4) family activities, 5) the child's health, 6) the child's background, 7) the child's family, and 8) the families household. This study focused only on questions addressing the child's schooling and the characteristics of the family.

Predictor Variables

Child's Schooling

Type of School

Respondents were asked, "What type of school does this child attend?". Responses included 1) Private, Catholic; 2) Private, religious but not Catholic; 3) Private, non-religious; and 4) Public school.

Current Grade

Respondents were asked to report the child's current grade. Grades were coded as elementary school (grades 1 - 8) and non-elementary school (grades 9 - 12).

Enjoyment of School

Respondents were asked to rate their agreement with the following statement "The child enjoys school" using a four-point Likert scale (1 strongly agree; 2 agree; 3 disagree, and 4 strongly disagree).

Childs Grades

Respondents were asked to tell about the child's grades over the course of the 
school year across all subjects using a metric from mostly all. As to mostly all Ds with a category indicating the child was not graded using this metric system.

Parental Engagement and Children's Behavior in School

Respondents were asked to report the number of times they were contacted about their child's behavior problems, problems with school work, very good behavior, and very good schoolwork. Items were recoded to reflect the frequency of the event: 1 = very frequently ( 31 - 99 times), 2 = frequently (13 - 30 times), and 3 = infrequently ( 1 - 12 times).

\section{Absenteeism}

Absenteeism was assessed by asking respondents to indicate how many days the child had been absent since the beginning of the school year. Items were recoded to reflect the frequency of the event: $1=$ non-chronic absenteeism $(<21$ days) and chronic absenteeism (21 - 130 days).

\section{Outcome Variable}

Academic Achievement

The academic achievement variable was constructed from children's grades into higher achievement and low achievement: high achievement $=$ As and Bs and low achievement $=$ Cs and Ds.

\subsection{Statistical Analysis}

Data for this study were analyzed using PASW Statistics 18.0 Complex Samples module. Descriptive statistics were calculated for categorical and dichotomous variables. Spearman correlations and logistic regressions were computed to examine the relationship between the predictor variables and the outcome variable.

Weighted Data

The data for this study were weighted using the NHES:2012 Parent and Family Involvement in Education full sample weight (FPWT) and the nesting variables (PSTRATUM, PPSU). The weights are used to produce unbiased and consistent estimates of national totals (Noel, Stark, \& Redford, 2013).

\section{Results}

\subsection{Family Characteristics and School Choice}

Demographic data for this study consisted of the child's race and gender, their attendance in public or private school, the educational achievement of the parent or guardian interviewed as well as their employment status (Table 1 for an overview of family characteristics).

\subsection{Enjoyment of School}

Descriptive statistics revealed that $41.4 \%$ and $58.6 \%$ of parents and guardians of high-achieving African-American boys who attended Catholic elementary school respectively reported that they strongly agreed and agreed that their boys enjoyed school. None of the parents of high-achieving boys reported that their boys did not enjoy school. Furthermore, none of the parents of low achieving 
boys attending Catholic school responded to this question. In contrast, 48.7\% and $44.9 \%$ of parents and guardians of high-achieving African-American boys attending public school strongly agreed and agreed that their sons enjoyed school. $6.4 \%$ of the parents and guardians of high-achieving boys revealed that their sons did not enjoy school. On the other hand, of the parents and guardians whose sons attended public school and were low-achievers, $6.8 \%$ and $63.0 \%$ strongly agreed and agreed respectively that their sons enjoyed school.

\subsection{School Attendance}

Descriptive statistics indicated that $100.0 \%$ of parents and guardians reported that their high-achieving, as well as low-achieving African-American boys attending Catholic elementary school, did not exhibit a pattern of chronic absenteeism.

In contrast, $99.5 \%$ of parents and guardians of high-achieving African-American boys and $94.8 \%$ of low-achieving boys attending public reported their sons did not exhibit a pattern of chronic absenteeism. On the other hand parents of low-achieving African-American boys attending public school reported 5.2\% of their sons being chronically absent from school.

Table 1. Family characteristics and school choice for African-American boys in elementary school.

\begin{tabular}{|c|c|c|}
\hline Characteristics & $\mathrm{N}$ & $\%^{\mathrm{c}}$ \\
\hline \multicolumn{3}{|l|}{ Type of School } \\
\hline Catholic & $\begin{array}{c}19 \\
555\end{array}$ & 17.1 \\
\hline Public & 555 & \\
\hline \multicolumn{3}{|l|}{ Parent/Guardian Level of Education } \\
\hline \multicolumn{3}{|l|}{$8^{\text {th }}$ grade } \\
\hline Catholic & ---- & ---- \\
\hline Public & 12 & 9.8 \\
\hline \multicolumn{3}{|l|}{ High school, but no diploma } \\
\hline Catholic & ---- & --- \\
\hline Public & 44 & 20.7 \\
\hline \multicolumn{3}{|c|}{ High school diploma or equivalent (GED) } \\
\hline Catholic & 1 & 50.0 \\
\hline Public & 91 & 17.8 \\
\hline \multicolumn{3}{|c|}{ Vocational diploma after high school } \\
\hline Catholic & 1 & 10.0 \\
\hline Public & 23 & 13.1 \\
\hline \multicolumn{3}{|l|}{ Some college, but no degree } \\
\hline Catholic & 2 & 7.7 \\
\hline Public & 141 & 22.9 \\
\hline
\end{tabular}




\section{Continued}

\section{Associate's degree (AA, AS) \\ Catholic}

Public

Bachelor's degree (BA, BS)

Catholic

Public

Some graduate or professional education, but no

degree

Catholic

Public

20

Master's degree (MA, MS)

Catholic

Public

35

Doctorate degree (PhD, EdD)

Catholic

Public

Employment Status

Employed for payor income

Catholic

Public

Self-employed

Catholic

Public

Unemployed or out of work

Catholic

Public

26.4

Full-time student

Catholic

Public

Stay at home parent

Catholic

Public

1

31

4.0

Retired

Catholic

Public

19

31.1

Disabled or unable to work

Catholic

Public
6

4.1




\subsection{Relationship between School Climate and Academic Achievement}

Spearman rho correlations were calculated between variables associated with school climate and academic achievement (see Table 2). Children's overall grades were positively associated with enjoyment of school, parents being contacted for good behavior, behavioral problems, problems with schoolwork, as well as with attendance. Overall grades were negatively associated with parents being contacted for problems with school work. Weak positive correlations were found between enjoyment of school, being contacted for behavior problems, problems with school work, and attendance. In contrast, negative associations were found between children's enjoyment of school and parents being contacted about very good behavior and very good schoolwork. A strong positive correlation was found between parents being contacted for very good behavior as well for being contacted for very good schoolwork. Weaker positive correlations were found between being contacted for behavior problems and being contacted for very good behavior, very good school work, and the number of days absent from school. A moderate correlation was found between children's problems with school work and their behavior problems. Finally, a weak positive association was found between being contacted for the child having very good school work and days absent from school.

\subsection{School Climate and Academic Achievement}

Logistic regression was computed to predict academic achievement from the type of school attended. The Nagelkerke $\mathrm{R}^{2}$ change $=(.022)$ provides an estimate of the amount of variance within the dependent variables accounted for by the model. The model correctly classified $72.0 \%$ of the cases. Wald statistics indicated that school type significantly predicted academic achievement, $X^{2}(1)=$ $5.560, p<.01$. The model predicted that the odds of being a high achiever was 13.620 times higher for African-American boys attending Catholic school than for boys attending public school.

Table 2. Spearman rho correlations between school climate and child's overall grades.

\begin{tabular}{|c|c|c|c|c|c|c|}
\hline Variables & $2(\mathrm{ES})$ & $3(\mathrm{BP})$ & 4 (PSW) & 5 (VGB) & 6 (VGSW) & 7 (AS) \\
\hline 1) Child's overall grades (OG) & $.292^{* *}$ & $.289^{* *}$ & $.363^{* *}$ & $.032^{* *}$ & $-.018^{*}$ & $.186^{* *}$ \\
\hline 2) Enjoyment of school (ES) & & $.250^{* *}$ & $.284^{* *}$ & $-.085^{* *}$ & $-.101^{* *}$ & $.222^{* *}$ \\
\hline 3) Contacted for behavior problems (BP) & & & $.407^{* *}$ & $.158^{* *}$ & $.132^{* *}$ & $.155^{* *}$ \\
\hline 4) Contacted for problems with school work (PSW) & & & & $.148^{* *}$ & $.117^{* *}$ & $.160^{* *}$ \\
\hline 5) Contacted for very good behavior (VGB) & & & & & $.810^{* *}$ & $.047^{* *}$ \\
\hline 6) Contacted for very good school work (VGSW) & & & & & & $.041^{* *}$ \\
\hline 7) Days absent from school (AS) & & & & & & ------ \\
\hline
\end{tabular}

${ }^{* *} p<.01$ level (2-tailed). ${ }^{*} p<.05$ level (2-tailed). 
Furthermore, logistic regression was computed to assess whether the enjoyment of school predicted higher academic success. The Nagelkerke $R^{2}$ change $=(.239)$. The model correctly classified $75.9 \%$ of the cases. Wald statistics indicated that enjoyment of school significantly predicted higher academic achievement. $X^{2}(1)=$ $61.700, p<.001$. The model predicted that the odds of enjoying school were 3.913 times higher for high achieving African-American boys than low-achieving African-American boys.

To assess whether absenteeism predicted higher academic achievement, an additional logistic regression was computed using the dichotomous variable for chronic absenteeism. The Nagelkerke $\mathrm{R}^{2}$ change $=(.040)$. The model correctly estimated $69.3 \%$ of the cases. Wald statistics indicated that the number of days absent from school predicted academic achievement. $X^{2}(1)=8.384, p<.004$. The model predicted that the odds of not exhibiting chronic absenteeism was 11.43 times higher for high achieving African-American boys than low-achieving African-American boys.

Finally, to assess the contribution of multiple covariates reflecting school climate on the academic achievement of African-American boys attending elementary school a logistic regression was conducted to determine which independent variables (type of school, enjoyment of school, gender, absences from school, and parents/guardians being contacted for behavior problems, problems with school work, very good school behavior, and very good school work) predicted academic achievement (high versus low achievement). The Nagelkerke $\mathrm{R}^{2}$ change $=(.404)$. The model correctly classified $81.2 \%$ of the cases. Regression coefficients are presented in Table 3. Wald statistics indicated that five of the variables (enjoyment of school, absences from school, parents/guardians being contacted for behavioral problems in school, problems with school work, and for the parent/guardian being contacted for their child having very good school work) significantly predicted academic achievement. High achieving African-American boys were 1.117 times more likely to have parents who were contacted when their sons were having problems with schoolwork than their low-achieving peers. The odds ratios for parents being contacted for their son's production of good school work was fairly low. There were no significant differences in the type of school and the parent being contacted for very good behavior.

\section{Discussion}

The goal of the present study was to examine the relationship between school climate and the academic achievement of African-American boys attending Catholic and public elementary schools. This study contributes to the existing research by focusing on the role of school climate in shaping the academic success of African-American boys during the elementary school years.

Using data from the National Household Education Survey the results from this study suggest that parents who choose to send their children to Catholic school are in many ways similar to parents who send their children to public 
Table 3. Logistic regression of high and low achieving African-American boys attending catholic and public elementary school.

\begin{tabular}{llllll}
\hline Characteristic & $\begin{array}{l}\text { Wald Chi Square } \\
\text { Coefficient }\end{array}$ & SE & p value & Odds Ratio & $\begin{array}{l}\text { 95\% Confidence } \\
\text { Interval Upper Lower }\end{array}$ \\
\hline Catholic vs Public school & .760 & .684 & .383 & 1.815 & .4756 .932 \\
Parent contacted for behavior problems in school & 5.184 & .048 & .023 & 1.117 & 1.0151 .228 \\
Parent contacted for problems with school work & 17.436 & .092 & .000 & 1.466 & 1.2251 .755 \\
Parent contacted when the child had very good behavior & .718 & .074 & .397 & 1.065 & .9211 .232 \\
Parent contacted when the child produces very good school work & 11.724 & .116 & .001 & .673 & .536 .844 \\
Child's enjoyment of school & 46.941 & .172 & .000 & 3.242 & 2.3154 .538 \\
Absenteeism & 11.722 & .031 & .001 & 1.114 & 1.0471 .184
\end{tabular}

school with the exception that none of the parents of children attending Catholic reported that they were self-employed, unemployed or out of work, full-time students, or disabled and unable to work. It may very well be that because parents must pay for their children to attend Catholic school being unemployed would pose a hardship, making it difficult for them to pay the tuition, therefore making it impossible for their child to continue to attend the school.

In addition, the results from this study supported previous research findings that suggest that academic achievement is related to school climate (York, 1996; Fenzel \& Domingues, 2009; COSEBOC, 2013; Barbarin, et al., 2014). The findings suggest that when children enjoy school, they tend to have better academic outcomes (Fenzel \& Domingues, 2009; Harris \& Graves, 2010). Moreover, the strong correlation between parents and guardians being contacted when children exhibit very good school work and a moderate correlation when children exhibit behavior problems and are contacted for problems with their school work suggests that it may be the act of "contacting" the parent, and the parent's engagement that has a positive effect on the academic outcomes of African-American boys in elementary school. These findings again support previous research that has demonstrated that when teachers and schools attempt to maintain relationships with African-American parents through open communication by involving them in school events and other activities these interactions provide a foundation for African-American boys to experience greater academic success (Barbarin et al., 2014).

Furthermore, the inverse relationship between boy's overall grades and parents and guardians being contacted for very good school work suggests that when teachers or other education personnel feel the child is doing well in school they spend less time communicating with parents. While on this surface this appears to be a logical outcome, for African-American boys interacting less with parents and guardians may lead to unintended consequences. As Barbarin et al. (2014) have pointed out African-American boys appear to perform better in school when their parents are engaged and communicate with teachers. Therefore, regardless of how well African-American boys may appear to be doing in school continued interaction and communication with parents and 
guardians remains to be a critical factor (COSEBOC, 2013; Barbarin et al., 2014).

Finally, the analyses of parent and guardian's reporting about the school climate in Catholic and public schools and African-Americans overall academic achievement revealed that parent's perceptions were related to academic achievement. For example, regardless of whether boys attended Catholic or public school high achieving boys tended to report greater enjoyment of school. These results support previous research findings that have suggested that regardless of school type, when children perceive that schools are enjoyable and fair, they tend to succeed academically (Fenzel \& Domigues, 2009; Swaminathan, 2004; Towns et al., 2001; Waxman \& Huang, 1998). In addition, school attendance significantly influenced the academic achievement of African-American boys attending Catholic school, with boys in Catholic schools missing fewer days and high achieving African-American boys regardless of school type missing fewer days of school. As Barbarin et al. (2014) point out, African-American boys are more likely to cut classes and skip school than their White peers. Their behavior, however, may be the consequence of their perception of being mistreated. That being the case, it may well be that African-American boys who attend Catholic schools may not hold such attitudes, thereby enjoying their school experience more, which may lead to better academic outcomes. Thus the "Catholic School Effect" may be providing a school climate that fosters enjoyment of learning and perceived fairness, which in turn leads to African-American boys wanting to attend a school that may ultimately lead to better academic achievement.

\section{Limitations of the Study}

While the current study has several strengths and adds new knowledge to the field, nevertheless, there are several limitations. First, while the PPI is a nationally representative data set and provides information about parents' beliefs about their children's schooling, the information is nevertheless self-reported and therefore limited. For example, information about children's academic achievement is based on parent responses rather than on standardized measures and, therefore, may not accurately reflect performance. Furthermore, previous research has examined the effects discipline policies, teacher's salaries, teacher's credentials (Cibulka, O’Brien, \& Zewe, 1982), staff personal and social values (Benson et al., 1986) and curriculum offerings (Bryk, Lee, \& Holland, 1993) on the academic achievement of African-American students. The current data set does not contain a set of variables that allow for the assessment of the above-mentioned characteristics that make up the school climate, therefore making it difficult to address these issues.

Additionally, this study did not examine the relationship between parent engagement and the academic of African-American boys. Previous research has found that the beliefs African-American parents hold concerning academic achievements, such as focusing on the importance of academic skills, are correlated with higher achievement mathematics and reading skills in their boys (Joe \& Davis, 2009). That being said, future research should examine the relationship between parental engagement and the academic achievement of 
African-American boys attending Catholic and public elementary schools. Furthermore, the study did not address the relationship between religious education and academic performance which has been found to have a positive effect on achievement for African-American males (Jett, 2010), this is partly because the dataset does not contain such a variable. The inclusion of such information is critical for future studies. Finally, while this study examined the differences in school climates within Catholic and public schools and their relationship to the academic performance of African-American boys, it did not consider alternative types of private schools such as other religious schools or private non-religious schools. Examining these alternatives is critical if one wants to argue that there is a "Catholic School Effect" rather than a "private" school effect. In moving forward, future studies should include these alternatives to address this issue.

\section{Conclusion}

As the United States continues to grapple with the persistent achievement gap that remains between African-American children and their White, Asian, and Latino peers, particularly for boys, it becomes incumbent upon the nation to build upon models of education that have consistently demonstrated their ability to provide African-American youth with a solid academic foundation so they can succeed. Catholic schools appear to be one such model. Catholic schools have been successfully educating African-American youth since the $1800 \mathrm{~s}$ (Chineworth, 1996). While studies have demonstrated differences across Catholic schools in academic preparation (Fenzel \& Domingues, 2009), Catholic schools nevertheless have overall provided a better foundation for low-income minority students than other alternatives (Keith \& Page, 1985; Fenzel \& Dominguez, 2009). While many models have tried to emulate Catholic schools in providing smaller classes and better quality school climates, differences nevertheless remain (Covey, 1992). Those differences that remain may in part be due to what has been referred to as Catholic school culture (Cook, 2001), a culture rooted in the identity of Catholic schools to foster academic excellence, religious mission, and globalness/multiculturalism with a faith-based mission being at the very core of Catholic tradition. One such notable advocate for Catholic education for African-American children was Katharine Drexel. Katharine Drexel donated millions of dollars of her own money to develop schools to educate African-American and Native American children in a time when to do so was not in vogue. Her desire was not based on making money and the privatization of education because she was giving away her fortune; instead, it was based on a desire to correct some of America's history of discrimination and educate children to provide them with a future. Katharine's goal, based on her faith commitment, was to provide African-American children not only with quality academic education but also one that would address their spiritual, physical, and social-emotional needs. In 1915 she would go on to found Xavier University, the first Historically Black Catholic University, to provide access to 
higher education for African-Americans (Dunn, 1960). It short, Katharine Drexel's vision was to educate the whole child, drawing on the strengths of the community to provide African-American children with the opportunity to become full and participating citizens of the United States (Lipperini, 2013). Previous research has demonstrated that African-Americans are a resilient people and that for many of them, religion and spirituality is at the core of their identity (Belgrave \& Allison, 2014). Moreover, positive relationships have been demonstrated between academic achievement and spirituality for African-American males (Jett, 2010). Therefore going forward, if policymakers and educators wish to emulate the success that Catholic schools have demonstrated with low-income minority students, they must not only reduce class size and ensure teachers have appropriate teaching credentials; they must also consider educating the whole child addressing their mental, physical, and spiritual needs.

\section{Conflicts of Interest}

The author declares no conflicts of interest regarding the publication of this paper.

\section{References}

Barbarin, O. A., Chinn, L., \& Wright, Y. F. (2014). Chapter Ten Creating Developmentally Auspicious School Environments for African American Boys. Advances in Child Development and Behavior, 47, 333-365. https://doi.org/10.1016/bs.acdb.2014.04.003

Belgrave, F. Z., \& Allison, K. W. (2014). African American Psychology: From Africa to America (3rd ed.). Thousand Oaks, CA: Sage Publications, Inc.

Belgrave, F. Z., \& Brevard, J. K. (2015). African American Boys. Identity, Culture, and Development. New York, NY: Springer Science + Business Media. https://doi.org/10.1007/978-1-4939-1717-4

Benson, P. L., Yeager, R. J., Wood, P. K., Guerra, M. J., \& Manno, B. V. (1986). Catholic High Schools: Their Impact on Low-Income Students. Washington DC: National Catholic Education Association.

Byrk, A. S., Lee, V., \& Holland, P. (1993). Catholic Schools and the Common Good. Boston, MA: Harvard University Press.

Chineworth, M. A. (1996). Rise " $n$ " Shine: Catholic Education and the African-American Community. Washington DC: National Catholic Educational Association.

Cibulka, J. G., O'Brien, T. J., \& Zewe, D. (1982). Inner-City Private Elementary Schools: A Study. Milwaukee, WI: Marquette University Press.

Cook, T. J. (2001). Architects of Catholic Culture: Designing and Building Catholic Culture in Catholic Schools. The NCEA Catholic Educational Leadership Monograph Series: ERIC.

COSEBOC (2013). Standards and Promising Practices for Schools Educating Boys of Color: Executive Summary. Boston, MA: Coalition of Schools Educating Boys of Color. http://coseboc.org/sites/coseboc.org/files/assets/Executive-Summary-2014.pdf

Covey, J. (1992). Catholic Schools Make a Difference: Twenty-Five Years of Research. Washington DC: National Catholic Education Association

Dunne, W. (1960). The Roman Catholic Church: The Rationale and Policies Underlying the Maintenance of Higher Institutions for Negroes. Journal of Negro Education, 29, 
307-314. https://doi.org/10.2307/2293647

Fenzel, L. M., \& Domingues, J. (2009). Educating Urban African American Children Placed at Risk: A Comparison of Two Types of Catholic Middle Schools. Journal of Catholic Education, 13, 30-52. https://doi.org/10.15365/joce.1301032013

Fenzel, L. M., \& Monteith, R. H. (2008). Successful Alternative Middle Schools for Urban Minority Children: A Study of Nativity Schools. Journal of Education for Students Placed at Risk, 13, 381-401. https://doi.org/10.1080/10824660802427686

Greeley, A. M. (1982). Catholic High Schools and Minority Students. New Brunswick, NJ: Transaction Publishers.

Green, P. (2011). African Americans in Urban Catholic Schools: Faith, Leadership and Persistence in Pursuit of Educational Opportunity. The Urban Review, 43, 436-464. http://link.galegroup.com/apps/doc/A264585567/AONE? u=cuny_hunter\&sid=AONE \&xid=ab082341 https://doi.org/10.1007/s11256-010-0171-9

Harris, T. S., \& Graves Jr., S. L. (2010). The Influence of Cultural Capital Transmission on Reading Achievement in African American Fifth Grade Boys. The Journal of Negro Education, 79, 447-457. https://doi.org/10.1037/e631012010-001

Hoffer, T., Greeley, A. M., \& Coleman, J. S. (1985). Achievement Growth in Public and Catholic Schools. Sociology of Education, 58, 74-97. https://doi.org/10.2307/2112249

Irvine, J. J., \& Foster, M. (1996). Growing Up African American in Catholic Schools. New York: Teachers College Press.

Jett, C. C. (2010). “Many Are Called, But Few Are Chosen”: The Role of Spirituality and Religion in the Educational Outcomes of "Chosen" African American Male Mathematics Majors. Journal of Negro Education, 79, 324-334.

Joe, E. M., \& Davis, J. E. (2009). Parental Influence, School Readiness, and Early Academic Achievement of African American Boys. The Journal of Negro Education, 78, 260-276.

Keith, T. Z., \& Page, E. B. (1985). Do Catholic High Schools Improve Minority Student Achievement? American Educational Research Journal, 22, 337-349. https://doi.org/10.3102/00028312022003337

Lipperini, P. T. (2013). Privileged to Educate: Katharine Drexel and Catholic Social Teaching-An Embodied Pedagogy. Religious Education, 108, 392-402. https://doi.org/10.1080/00344087.2013.805032

Marsh, K., Chaney, C., \& Jones, D. (2012). The Strengths of High-Achieving Black High School Students in a Racially Diverse Setting. Journal of Negro Education, 81, 39-51. http://search.ebscohost.com/login.aspx?direct=true\&db=eric\&AN=EJ973543\&site=eho st-live https://doi.org/10.7709/jnegroeducation.81.1.0039

National Black Catholic Congress (2012). The 2012 Congress 11 Pastoral Plan of Action. https://www.nbccongress.org/pastoral-plans.html

National Education Association NEA (2011). Race against Time: Educating Black Boys. Washington DC: Author.

Noel, A., Stark, P., \& Redford, J. (2013). Parent and Family Involvement in Education, from the National Household Education Surveys Program of 2012 (NCES 2013-028.REV2). Washington DC: National Center for Education Statistics, Institute of Education Sciences, U.S. Department of Education. http://nces.ed.gov/pubsearch

Schott Foundation for Public Education (2015). Black Lives Matter: The Schott 50 State Report on Public Education and Black Males. 
http://schottfoundation.org/resources/black-lives-matter-schott-50-state-report-public -education-and-black-males

Swaminathan, R. (2004). "It's My Place": Student Perspectives on Urban School Effectiveness. School Effectiveness and School Improvement, 15, 33-63. https://doi.org/10.1076/sesi.15.1.33.27493

Towns, D. P., Cole-Henderson, B., \& Serpell, Z. (2001). The Journey to Urban School Success: Going the Extra Mile. Journal of Negro Education, 70, 4-18.

United States Conference of Catholic Bishops (USCCB) (2006). Renewing Our Commitment to Catholic Elementary and Secondary Schools in the Third Millennium. Journal of Catholic Education, 9. http://dx.doi.org/10.15365/joce.0903022013

United States Conference of Catholic Bishops (USCCB) (2015). Educating Today and Tomorrow a Renewing Passion: World Congress on Catholic Education. http://www.usccb.org/search.cfm

University-Community Partnerships at Michigan State (2004a). School Climate and Learning (Issue No. 31). East Lansing, MI: Author.

University-Community Partnerships at Michigan State (2004b). Characteristics of Effective Elementary Schools in Poverty Areas (Issue No. 29). East Lansing, MI: Author.

Waxman, H. C., \& Huang, S.-Y. L. (1998). Classroom Learning Environments in Urban Elementary, Middle, and High Schools. Learning Environments Research, 1, 95-113. https://doi.org/10.1023/A:1009940816549

York, D. E. (1996). The Academic Achievement of African Americans in Catholic Schools: A Review of the Literature. In J. J. Irvine, \& M. Foster (Eds.), Growing Up African American in Catholic Schools (pp. 11-46). New York: Teachers College. 